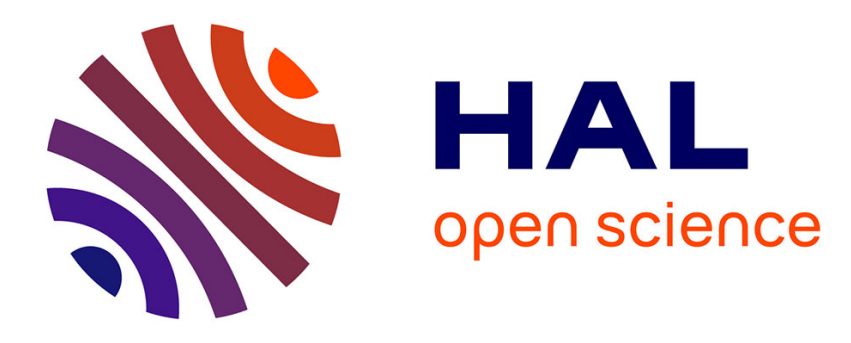

\title{
Optical measurement of the expansion of a laser plasma created on a planar microtarget
}

\author{
C. Popovics, R. Benattar
}

\section{To cite this version:}

C. Popovics, R. Benattar. Optical measurement of the expansion of a laser plasma created on a planar microtarget. Journal de Physique Lettres, 1982, 43 (17), pp.633-639. 10.1051/jphyslet:019820043017063300 . jpa-00232104

\section{HAL Id: jpa-00232104 https://hal.science/jpa-00232104}

Submitted on 1 Jan 1982

HAL is a multi-disciplinary open access archive for the deposit and dissemination of scientific research documents, whether they are published or not. The documents may come from teaching and research institutions in France or abroad, or from public or private research centers.
L'archive ouverte pluridisciplinaire HAL, est destinée au dépôt et à la diffusion de documents scientifiques de niveau recherche, publiés ou non, émanant des établissements d'enseignement et de recherche français ou étrangers, des laboratoires publics ou privés. 
Classification

Physics Abstracts

$52.50 \mathrm{~J}$

\title{
Optical measurement of the expansion of a laser plasma created on a planar microtarget
}

\author{
C. Popovics (*) and R. Benattar (*) \\ Laboratoire P.M.I., Groupe de Recherche no 29 du C.N.R.S., Ecole Polytechnique, \\ 91128 Palaiseau Cedex, France
}

(Reçu le 28 juin 1982, accepté le 19 juillet 1982)

\begin{abstract}
Résumé. - Pour mesurer par interférométrie la densité dans la couronne d'un plasma créé par laser, il faut utiliser de petites cibles afin d'atteindre la densité la plus élevée possible. Ici, nous avons choisi de créer un plasma au bout de micro-cylindres de même diamètre que la tache focale du laser. Avec ce type de cible, le plasma créé en dehors de la tache focale par conduction latérale est situé sur la périphérie du micro-cylindre et peut être sondé optiquement indépendamment du plasma principal.

En utilisant de telles cibles illuminées par une impulsion laser à néodyme de 1 à $3 \mathrm{~J}$ et de durée $50 \mathrm{ps}$, nous avons mis en évidence pendant l'impulsion laser, des effets non linéaires tels que modification du profil de densité et filamentation. Après l'impulsion laser, nous avons mesuré la distribution de densité, montrant que les isodensités ont une forme sphérique. Quelques pourcents de l'énergie laser incidente sont retrouvés dans l'expansion latérale d'un plasma de quelques électrons volts de température qui s'étend sur environ $100 \mu \mathrm{m}$ le long du micro-cylindre.
\end{abstract}

\begin{abstract}
Interferometric density measurements in the corona of a laser created plasma require small targets in order to reach the highest density possible. Here we have chosen to create the plasma on the end of microcylinders which diameter is of the size of the focal spot of the laser. With this type of target, the plasma created outside the focal spot of the laser by lateral conduction is located at the periphery of the microcylinder and can be optically probed separately from the main plasma. Using such targets illuminated with a $1-3 \mathrm{~J}, 50 \mathrm{ps}$ duration neodymium laser pulse, we have evidenced during the laser pulse non linear effects such as density profile modifications and filamentation. After the laser pulse, we have measured the density distribution showing that the density contours are nearly spherical. A few percent of the incident laser energy is found in a lateral plasma whose temperature is a few electron volts and which expands about $100 \mu \mathrm{m}$ along the microcylinder.
\end{abstract}

In laser target interaction, the energy transfer from the laser to the dense regions of the plasma is greatly dependent on what occurs in the corona. The knowledge of the parameters of this outside plasma, in particular its electronic density profile is important for the study of absorption and transport processes, and instabilities. The laser absorption is directly related to the density gradients in the subcritical and critical plasma, and the heat transfer across the laser axis or toward the dense regions depends on the presence of magnetic fields and suprathermal

(*) Contributing to the GRECO-ILM of the C.N.R.S. 
electrons. Density contours can be modified by these two last processes and also by instabilities. Optical probing and in particular interferometry is a good approach for the corona study as it gives in this region qualitatıve and quantitative informations on the contour lines and gradient scale lengths of the density.

In the case of the interaction of a laser beam at $1.06 \mu \mathrm{m}$ wavelength, the density profile around the cutoff density for the main beam can be measured by UV interferometry if the extension of the plasma is sufficiently small [1,3]. In the experiences on large planar targets, optical probing is difficult as the edges of the target and the large low density plasma alters the measurement of the centre of the plasma : indeed, a first source of error is the presence of diffraction fringes created by the edge of the target ; this can be eliminated by choosing a target with a large curvature instead of a plane target. Also, refraction may become so important that the probe beam does not reach the critical density for the main laser. Moreover, the contribution of the cold peripheric plasma to the interference order can become as important as the axial plasma one and introduce an important error on the measurement. Then, in order to measure the density on a planar target, we use as a target the end of a microcylinder which diameter is of the order of the focal spot diameter. For this type of target, the lateral expansion of the plasma is located on the circumference of the cylinder so the cold lateral plasma does not alter the axial plasma measurement, and it can itself be also measured.

The plasma is created by a neodymium laser $(\lambda=1.06 \mu \mathrm{m})$ on the end of glass cylinders of 50 or $100 \mu \mathrm{m}$ diameter. Pulse duration is $50 \mathrm{ps}$ and the incident energy varies between 1 and $3 \mathrm{~J}$, giving $5 \times 10^{14}$ to $1.5 \times 10^{15} \mathrm{~W} / \mathrm{cm}^{2}$ in a $70 \mu \mathrm{m}$ focal spot. A Wollaston interferometer [4] is illuminated by a $0.26 \mu \mathrm{m}$ wavelength probe beam of $25 \mathrm{ps}$ pulse duration. The temporal evolution of the plasma is measured by varying the delay between the probe beam and the main beam ( $\Delta t=0$ when the two maxima are simultaneous). Spatial resolution is limited to $5 \mu \mathrm{m}$ by the precision of the set up of the target in the object plane of the imaging microscope.

The observation of the plasma evolution shows well separated axial and lateral expansion. During and just after the laser pulse, the axial expansion is very fast, and non linear effects occur in a sharp density gradient. In this first stage, interferometric measurements are not quantitative and are inferpreted as shadowgraphy. In a second stage, the expansion becomes more quiet and quantitative density measurements are then possible. A lateral plasma is rapidly established along the cylindrical target, and can be studied during the two stages of the expansion.

In the first stage of rapid expansion, during and after the laser pulse, interferograms present a few closed up fringes around a opaque zone. This indicates a very sharp density gradient $\left(L_{e}<5 \mu \mathrm{m}\right)$ which is not resolved in the experiment. Simultaneously, interferograms evidence non linear effects : figure 1 shows a density crater which can be associated to the radiation pressure of the laser. The importance of the ponderomotive effects in the experimental conditions



Fig. 1. - Formation of a density crater on a target of $50 \mu \mathrm{m}$ diameter with a $1.5 \times 10^{15} \mathrm{~W} / \mathrm{cm}^{2}$ laser intensity. The interferogram is obtained $30 \mathrm{ps}$ after the laser pulse maximum 
can be verified by evaluating the ratio $\alpha$ between the gradients of radiation pressure and kinetic pressure. The density gradient being of the same order as the laser wavelength, the ratio $\alpha$ can be written [5] :

$$
\alpha=\nabla P_{\mathrm{R}} / \nabla P_{\mathrm{e}} \simeq P_{\mathrm{R}} / P_{\mathrm{e}}=\left(2.1 \times 10^{-13} I_{0} \lambda^{2} / T_{\mathrm{e}}\right)^{1 / 2}
$$

with $I_{0}$ in W/cm $\mathrm{cm}^{2}, \lambda$ in $\mu \mathrm{m}$ and $T_{\mathrm{e}}$ in $\mathrm{eV}$. Taking $T_{\mathrm{e}}=1 \mathrm{keV}$, and the measured

$$
I_{0}=1.5 \times 10^{15} \mathrm{~W} / \mathrm{cm}^{2}
$$

we find $\alpha=0.56$, which means that the ponderomotive effects are important [6-7].

On figure 2 appears a more complex structure which can be attributed to a filamentation of the laser beam in the plasma. This structure, very similar to what is observed in other experiments [8], presents 8 to $9 \mu \mathrm{m}$ diameter filaments. The distance between the filaments is at least 20 to $25 \mu \mathrm{m}$. The filaments can be initiated by hot spots in the laser beam. The measured filaments diameter is in accordance with the calculation of stability of a filament propagating in a plasma [9]. Indeed, the stable diameter is :

$$
d_{\mathrm{f}}=2 \sqrt{2}\left(c / \omega_{\mathrm{p}}\right) \frac{\exp \left(v_{0}^{2} / 8 v_{\mathrm{t}}^{2}\right)}{v_{0} / 2 v_{\mathrm{t}}}
$$

where $\omega_{\mathrm{p}}$ is the local plasma frequency, $v_{0}$ the oscillating speed of an electron in the electromagnetic field, and $v_{\mathrm{t}}$ the thermal velocity. This gives

$$
d_{\mathrm{f}}=8 \mu \mathrm{m} \quad \text { for } \quad n_{\mathrm{e}}=n_{\mathrm{c}} / 10
$$

and

$$
d_{\mathrm{f}}=2.6 \mu \mathrm{m} \text { for } n_{\mathrm{e}}=n_{\mathrm{c}} .
$$

The $8 \mu \mathrm{m}$ diameter measured in the underdense plasma is close to the prediction, and the figure 2 shows that the filament diameter decreases when the density increases.

Although the exact position of an isodensity contour cannot be measured during and just after the laser pulse from the interferograms, we can show that the edge of the opaque zone can be associated to a density of the order of $5 \times 10^{19} \mathrm{~cm}^{-3}$ to $2 \times 10^{20} \mathrm{~cm}^{-3}$. Indeed, this transition corresponds to a sharp density gradient from the density of maximal penetration of the main beam until a density which is sufficiently small for the fringes be not much shifted. The opaque zone is characteristic of a region where the probe beam is refracted out of the imaging optics and must be associated to a density greater than $2 \times 10^{20} \mathrm{~cm}^{-3}$. The fringes which are not

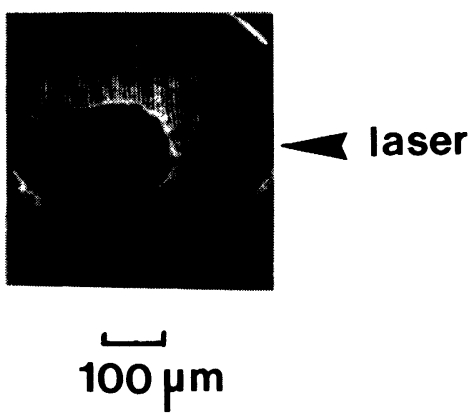

Fig. 2. - Filamentation of the subcritical plasma. (Target diameter : $100 \mu \mathrm{m}$, laser intensity : $9 \times 10^{14} \mathrm{~W} / \mathrm{cm}^{2}$.) The filaments are evidenced by a density jump and a absorption of the probe beam. 


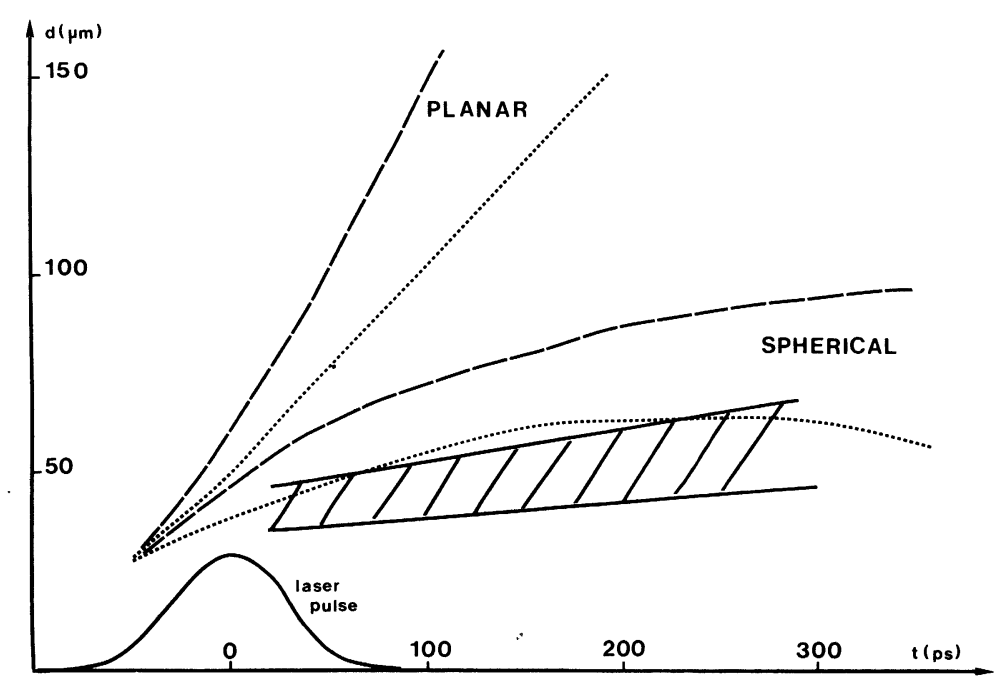

Fig. 3. - Axial expansion of the plasma. The position of the edge of the dark zone surrounding the target is reported in the dashed area. It is compared to the evolution of the $5 \times 10^{19}$ and $2 \times 10^{20} \mathrm{~cm}^{-3}$ isodensities calculated in a spherical planar calculation with the hydrocode FILM (-— : $5 \times 10^{19} \mathrm{~cm}^{-3}$; -.-: $: 2 \times 10^{20} \mathrm{~cm}^{-3}$ ).

much shifted correspond to a low density plasma. Figure $4 c$ indicates that a density greater or of the order of $5 \times 10^{19} \mathrm{~cm}^{-3}$ can be reasonably associated to the low density side of the sharp gradient. So the temporal evolution of the opaque zone can be compared to the plasma evolution calculated with an hydrocode. The calculation is done with the monodimensional hydrocode FILM [5-10] with a laser intensity of $5 \times 10^{14} \mathrm{~W} / \mathrm{cm}^{2}$ and a 50 ps duration pulse. The energy is absorbed by Inverse Bremsstrahlung ( $8 \%$ ) and locally at the critical surface $(10 \%)$. The thermal flux inhibition factor is 0.12 , value obtained for best fit of density profiles [3, 7]. Spherical and planar cases are considered. The spherical case is calculated with a target diameter of $50 \mu \mathrm{m}$ and for the comparison of spherical and planar calculations, the centre of symmetry is supposed to be on the planar target surface.

On figure 3, we have reported the density contours $5 \times 10^{19} \mathrm{~cm}^{-3}$ and $2 \times 10^{20} \mathrm{~cm}^{-3}$ calculated in the spherical and planar case. We have also indicated by hatchings the position of the dark zone. This comparison shows that after the laser pulse, the plasma expands much less than the prediction of the planar simulation, and is better represented by the spherical model. On the other hand, during the laser pulse, the planar and spherical models give a similar expansion, and the experiment is not conclusive on the type of geometry of the plasma.

The analysis of the interferograms obtained after the laser pulse show also that the subcritical plasma expands spherically. Figure 4 shows the interferogram obtained 210 ps after the maximum of the laser pulse, on a $100 \mu \mathrm{m}$ diameter target, and the results obtained from Abel inversion of the interferogram. The density profile (Fig. $4 \mathrm{c}$ ) has a $13 \pm 5 \mu \mathrm{m}$ gradient scale length at half critical density. The isodensity contours show clearly a spherical symmetry around a centre which moves off from the target during the expansion. The plasma diameter is of the same order as the focal spot diameter.

In this experiment, we have also measured the lateral expansion of the plasma which can be reached from the study of the plasma created on the periphery of the cylindrical target, on a non irradiated area. Figure 5 is the superposition of two interferograms, obtained before the laser shot (initial target image) and during the laser shot $(\Delta t=90 \mathrm{ps})$. It shows that the dark zone containing the expanding plasma has an extent of about $100 \mu \mathrm{m}$ along the microcylinder. The 

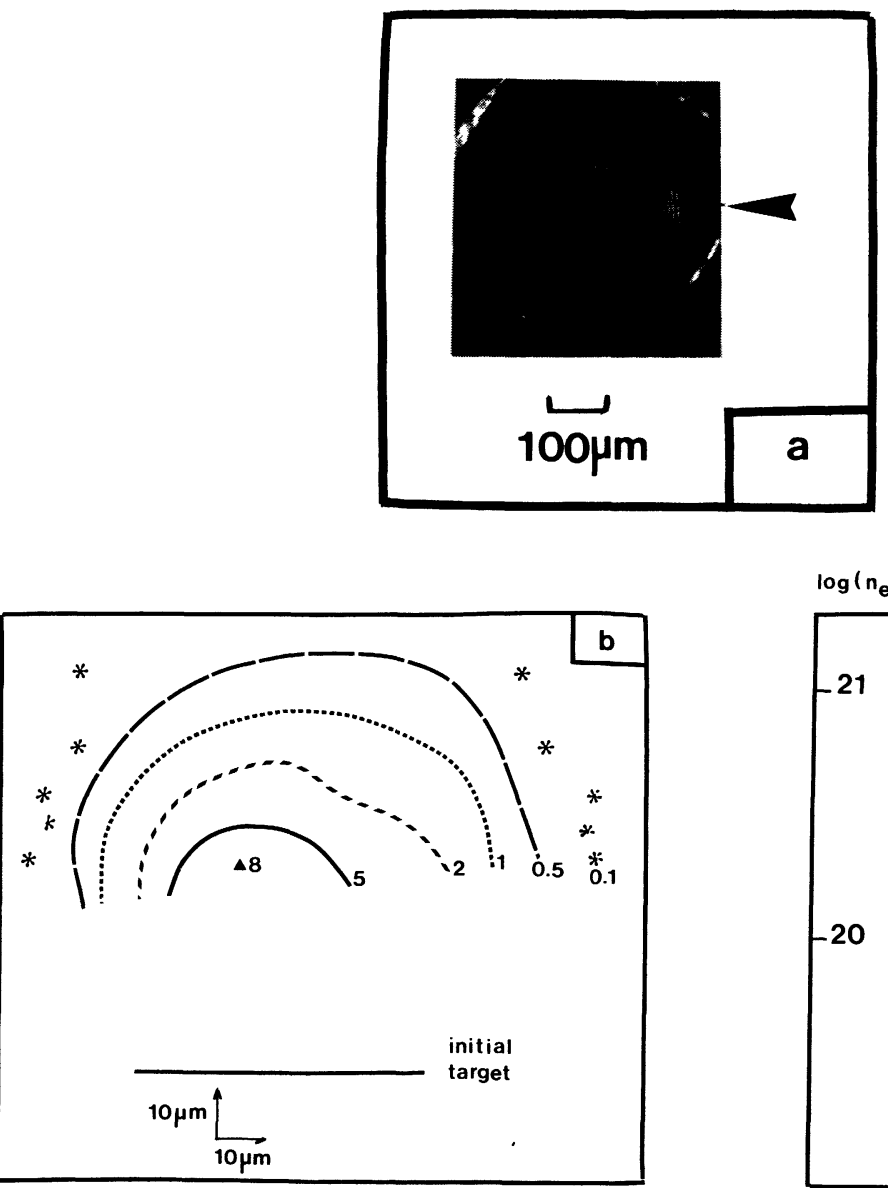

$\log \left(n_{e}\right)$

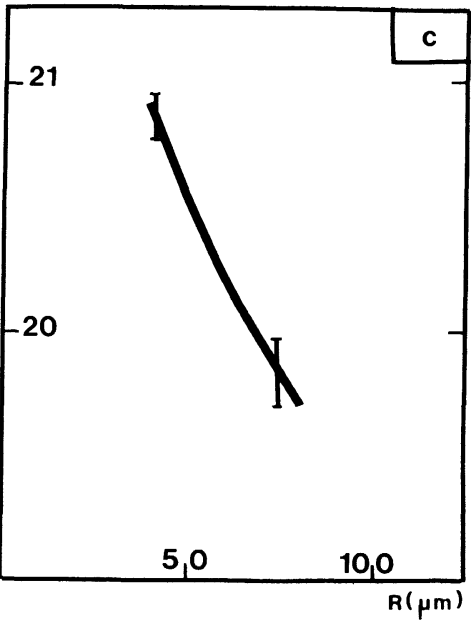

Fig. 4. - Sphericity of the subcritical plasma after the laser pulse $(\Delta t=210 \mathrm{ps})$. (Target diameter : $100 \mu \mathrm{m}$, laser intensity $: 10^{15} \mathrm{~W} / \mathrm{cm}^{2}$.) a) Interferogram. $b$ ) Isodensity contours densities are indicated in $10^{20} \mathrm{~cm}^{-3}$ unit. c) Density profile along the laser axis.



Fig. 5. - Lateral and axial expansion of the plasma. Two interferograms, obtained before the laser shot and $90 \mathrm{ps}$ after the laser maximum are superposed. In the dark region corresponding to the dense plasma expansion, one can see non shifted fringes recorded before the laser shot. 


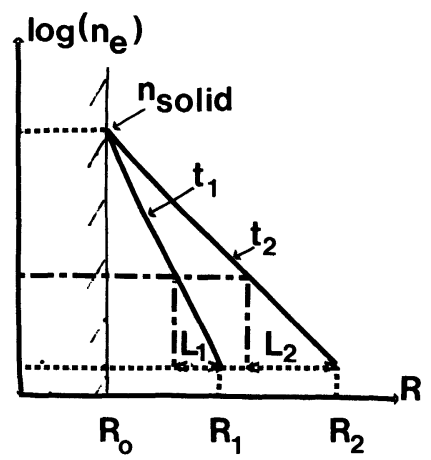

Fig. 6. - Self-similar expansion of the lateral plasma on a cylindrical target. From the measurement of the radius $R_{1}$ and $R_{2}$ of the plasma around the target at times $t_{1}$ and $t_{2}$, the density gradient scale lengths $L_{1}$ and $L_{2}$ are deduced.

measurement of the variation of the diameter of the cylinder in a non irradiated area leads to a value of the energy deposited by lateral transport along the target. Indeed, we may suppose that the radial expansion of the cylinder is self-similar in this case as the lateral plasma is heated by a thermal wave. Then the measurement of the diameter of the plasma at two different times gives the sound speed and the electronic temperature of the lateral plasma. In a cylindrical self-similar expansion, the sound speed is related to the density gradient scale lengths $L_{1}$ and $L_{2}$ measured at times $t_{1}$ and $t_{2}$ by :

$$
c_{\mathrm{s}}=\sqrt{2}\left(L_{2}-L_{1}\right) /\left(t_{2}-t_{1}\right) .
$$

Figure 6 indicates the way to deduce $L_{1}$ and $L_{2}$ from the position of the edge of the dark zone. Supposing that this frontier corresponds to a density of $5 \times 10^{19} \mathrm{~cm}^{-3}$ or $2 \times 10^{20} \mathrm{~cm}^{-3}$, the order of magnitude of the electronic temperature can be evaluated as :

- for a $100 \mu \mathrm{m}$ diameter target $T_{\mathrm{e}}=8 \mathrm{eV}$

- for a $50 \mu \mathrm{m}$ diameter target $T_{\mathrm{e}}=4$ to $20 \mathrm{eV}$.

The particles of the plasma are initially in a cylindrical corona which depth $e$ is the penetration of the thermal front. This depth can be evaluated to $1 \mu \mathrm{m}$ or less [11]. Then, we estimate the energy contained in the lateral plasma to :

$$
E_{\text {lat }}=n_{\mathrm{e}, \mathrm{sol}} \cdot k T_{\mathrm{e}} \cdot\left(\pi D_{0} e L\right)
$$

where $T_{\mathrm{e}}$ is the measured electronic temperature,

$n_{\mathrm{e}, \mathrm{sol}}$ is the electron density in the solid,

$D_{0}$ is the diameter of the initial target, and

$L$ is the length of the heated cylinder $(L \simeq 100 \mu \mathrm{m})$.

So, we find the order of magnitude of the laterally deposited energy, in percent of the incident laser energy :

— for a $100 \mu \mathrm{m}$ diameter target

$$
E_{\mathrm{lat}} / E_{\mathrm{inc}}=1.5 \%
$$

- for a $50 \mu \mathrm{m}$ diameter target

$$
E_{\text {lat }} / E_{\text {inc }}=0.5 \text { to } 2.5 \% \text {. }
$$


The above calculation could support the hypothesis of a lateral transport by suprathermal electrons. Indeed, the length of about $100 \mu \mathrm{m}$ of heated plasma corresponds to the range of suprathermal electrons, and the percentage of energy found in this lateral expansion is in agreement with previous experiments [12]. Nevertheless, a return current along the target could be also a possible mechanism to reach such lateral plasma conditions. And, in this case of targets of $50 \mu \mathrm{m}$ diameter, a part of the incident energy may also directly heat the periphery of the cylinder as the focal spot is larger than the target diameter.

In summary, this experiment of interaction on small size planar targets have evidenced the following points :

- during the laser pulse, non linear phenomena such as density crater formation and filamentation occur in the plasma;

- after the laser pulse, the subcritical plasma expands spherically;

- about $1 \%$ of the incident laser energy is deposited indirectly on the periphery of the cylindrical targets, on a distance of the order of $100 \mu \mathrm{m}$. This lateral heating can be attributed either to suprathermal electrons or to a return current in the target.

Acknowledgments. - We acknowledge assistance from the GRECO Interaction Laser Matière technical staff. We particularly appreciate support from and fruitful discussions with E. Fabre.

\section{References}

[1] Attwood, D. T., Sweeney, D. W., Auerbach, J. M., Lee, P. H. Y., Phys. Rev. Lett. 40 (1978) 184.

[2] Raven, A., Willi, O., Phys. Rev. Lett. 43 (1979) 278.

[3] Benattar, R., Popovics, C., Phys. Rev. Lett. 45 (1980) 1108.

[4] Benattar, R., Popovics, C., Sigel, R., Rev. Sci. Instrum. 50 (1979) 1583.

[5] Virmont, J., Pellat, R., Mora, P., Phys. Fluids 21 (1978) 567.

[6] Lee, K., Forslund, D. W., Kindel, J. M., Lindman, E. L., Phys. Fluids 20 (1977) 51.

[7] Popovics, C., Thèse de Doctorat d'Etat, Université Paris XI, no 2427 (1981).

[8] Willi, O., Rumsby, P. T., Hooker, C., Raven, A., Lin, Z. Q., Opt. Commun. 41 (1982) 110.

[9] Max, C. E., Phys. Fluids 19 (1976) 74.

[10] Shvarts, D., Jablon, C., Bernstein, I. B., Virmont, J., Mora, P., Nucl. Fusion 19 (1979) 1457.

[11] Amiranoff, F., Fabbro, R., Fabre, E., Garban, C., Virmont, J., Weinfeld, M., Phys. Rev. Lett. 43 (1979) 522.

RipIN, B. H. et al., Phys. Fluids 23 (1980) 1012.

[12] Amiranoff, F., Eidmann, K., Sigel, R., Fedosejevs, R., Maaswinkel, A., Kilkenny, J. D., HaRes, J. D., Bradley, D. K., MPQ Report no 60 (1982). 